\title{
Causes and Treatment of Varicose Recurrence in the Popliteal Region
}

\author{
Leonardo Corcos ${ }^{\mathrm{a}}$, Daniele Pontello ${ }^{\mathrm{a}, \mathrm{b}}$, Elio Ferlaino ${ }^{\mathrm{a}}$, Tommaso Spina ${ }^{\mathrm{a}}$, \\ Ugo Alonzo ${ }^{\mathrm{a}}$
}

\begin{abstract}
Background: In a previous study of 1,081 limbs affected with varicose recurrence (VR) at the saphenofemoral junction (SFJ) and at the sapheno-popliteal junction (SPJ), the anatomical causes were investigated. VR appeared to be due to inadequate diagnosis and surgery; neoangiogenesis appeared to play a minimal role. The so-called cavernoma was secondary to reflux and consisted with a complex collateral circulation (CC). Only 52 of 1,081 (4.8\%) studied limbs developed a VR at the SPJ, but the anatomical findings were poorly described. The aims of this study were: 1) to distinguish between VR at the SPJ and the ones caused by different sources of reflux, 2) the reliability of the preoperative DUS examination, and 3) the efficacy and safety of the treatment.
\end{abstract}

Methods: DUS examinations, surgery and sclerotherapy were performed by one single group of physicians. Nineteen of $207(9.1 \%)$ limbs affected with VR at the popliteal region were studied and treated. Most of the previous interventions performed in different vascular units (only one in our center) were high or low interruption +/- stripping of the small saphenous vein $(17 / 19,89.4 \%)$. VRs $>3 \mathrm{~mm}$ were treated by surgical high ligation and intraoperative sclerotherapy in $13 / 19(68.4 \%)$ and short invagination stripping in 1/19 (5.2\%); 4/19 $(21.0 \%)$ with VR $<3 \mathrm{~mm}$ were treated by sclerotherapy only. One patient $(5.2 \%)$ asked for conservative treatment. In all the cases, intraoperative and postoperative elastic compressions were applied. DUS and surgical findings were compared. Controls were performed by clinical and DUS examination (mean follow-up 3.8 years, min. 1, $\max .8)$

Results: Of 19 limbs observed, residual SPJ with a long saphenous stump (SS) was in 14 (73.6\%) and SPJ was absent in 5 (26.3\%): 1/19 $(5.2 \%)$ was a long SS with high outlet into the superficial femoral, one was $(5.2 \%)$ a long SS with high outlet into the medial accessory, and two $(10.5 \%)$ were non-saphenous popliteal perforator. More fre-

Manuscript submitted May 12, 2017, accepted June 9, 2017

${ }^{a}$ Non-invasive Vascular Laboratory and Department of General and Vascular Surgery of the Prosperius Institute for Clinical Research of Firenze, Italy

${ }^{b}$ Corresponding Author: Daniele Pontello, Non-invasive Vascular Laboratory and Department of General and Vascular Surgery of the Prosperius Institute for Clinical Research of Firenze, Italy. Email: danielepontello.md@gmail.com

doi: https://doi.org/10.14740/jcs325w quent residuals were in various combinations: SS 14 (73.6\%), nonsaphenous popliteal perforators $10(52.6 \%)$, intersaphenous communicating veins $3(15.7 \%)$, CC $4(21.0 \%)$, multiple sources of reflux 10 (52.6\%), and no suspected neoangiogenesis. DUS/surgical findings were overlapping in 13/14 re-operated limbs $(92.8 \%)$ : no post-treatment residual sources of reflux, short saphenous vein (SSV) permanently occluded by sclerotherapy in 17/18 (94.4\%); minor complications in 4/18 (27.7\%). Mean follow-up was 3.8 years (min. 1, max. 8).

Conclusions: The main causes of VR at the popliteal region are the postoperative anatomical residuals, mainly a long SS and perforators due to incomplete diagnosis and treatment and/or disease progression. Neovascularization was absent. CC appears to be a consequence of residual reflux. DUS is a reliable method for detecting the anatomical causes and indications for the treatment. Surgical revision combined with intraoperative sclerotherapy and elastic compression appeared to be a simple, effective and inexpensive procedure for the larger VR ( $>$ $3 \mathrm{~mm}$ ) at the PR. Sclerotherapy gave satisfactory results in the treatment of the smallest VR $(<3 \mathrm{~mm})$.

Keywords: Varicose; Veins; Recurrence; Anatomy; Popliteal; Duplex; Ultrasound; Surgery; Sclerotherapy

\section{Introduction}

A retrospective and prospective study of 1,081 limbs of 1,056 patients affected with postoperative varicose recurrence (VR) at the groin region and popliteal region (PR) was performed by 16 members of the Italian Society of Phlebolymphology from 2001 up to 2010 in order to verify the anatomical causes of VR at the saphenofemoral junction (SFJ) and sapheno-popliteal junction (SPJ) $[1,2]$. It was concluded that the anatomical residuals were the main causes for the onset of VR and that a detailed DUS examination was fundamental for recognizing such residuals before treatment or re-treatment. Neovascularization by neoangiogenesis, which is still often invoked for explaining high rates of postoperative VR, appeared to play a minimal role: five cases $(0.4 \%)$. The so-called cavernoma appeared to be represented by a complex collateral circulation (CC) caused by recurrent reflux from the residual incompetent veins.

The majority of the recurrent limbs (95.2\%) developed a VR at the groin and only $52(4.8 \%)$ at the PR. Therefore, a high 
Table 1. Distribution of VR at the Junctions in 1,831 Limbs of 1,760 Patients

\begin{tabular}{lll}
\hline Site of varicose recurrence & N & $\mathbf{\%}$ \\
\hline Limbs & 1,831 & 100 \\
Varicose recurrence SFJ - SPR & 207 & 11.3 \\
Varicose recurrence PR (isolated) & 19 & 1.0 \\
& $19 / 207$ & 9.1 \\
\hline
\end{tabular}

SFJ: sapheno-femoral junction; PR: popliteal region. Causistry of the years $2005-2016$.

attention was dedicated to the SFJ where a detailed description of every single anatomical finding was reported on the bases of the official nomenclature [3]. At the opposite, a lower interest for the VR at the SPJ/PR led to a poor anatomical description.

The aim of the study was to review the cases affected with a postoperative VR of the SPJ, or at the PR in the limbs where the SPJ is absent, to clarify the anatomical causes of VR, to compare the preoperative DUS findings with the intraoperative observation and to verify the efficacy and safety of the treatment.

\section{Patients and Methods}

A number of 207 limbs (11.3\%) of 195 patients (12 bilateral) affected with postoperative VR at the junctions, over a total number of 1,831 varicose treated limbs, were investigated and treated by one single group of physicians from January 2005 up to December 2015. Nineteen limbs of 17 patients, two bilateral, affected with VR of the PR out of 207 recurrent limbs at the junctions $(9.1 \%)$ were included $(19 / 1,831=1 \%$ overall $)$ (Table 1).

The study was performed on the bases of the principles outlined in the Declaration of Helsinki, the protocol and informed consent, which was signed by every single patient, and were approved by the Institutional Review Board.

Limbs previously subjected to the treatment of isolated peripheral varicose veins, the ones presenting recurrence of peripheral veins or isolated incompetence of leg perforators, deep venous insufficiency, pelvic reflux, congenital malformations, complications such as deep or superficial venous thrombosis, post-thrombotic syndrome, chronic and acute lymphedema, were excluded.

The limbs were studied by clinical and DUS investigation (Sonoscape 1000, Sonomed Roma ${ }^{\circledR} ; 7.5 \mathrm{mHz}$ probes). The age of the patients, the elapsed time between the first intervention and the occurrence of the VR, the side of the limb, the presence of symptoms from venous insufficiency, the clinical feature determined on the basis of CEAP classification, and the procedures performed at the first intervention are shown in Table 2. The first surgical treatment consisted with a high or low interruption $+/$ - short saphenous vein (SSV) stripping in the majority of the cases $(17 / 19=89.4 \%)$, including the ones subjected to the so-called CHIVA cure [4]. Two patients' limbs developed a VR at the PR after endovenous laser ablation (EVLA) of the SSV.
Table 2. Characteristics of 19 Limbs of 17 Patients Affected With Varicose Recurrence (VR) at the PR

\begin{tabular}{llll}
\hline & Mean & Min. & Max. \\
\hline Patients (17) & & & \\
Years of age & 38.8 & 27 & 73 \\
Years from surgery and VR & 4.8 & 1 & 12 \\
& $\mathrm{~N}$ & $\%$ \\
Patients & 17 & 100 \\
\hline Males & 7 & 41.1 \\
\hline Females & 10 & 58.8 \\
Symptomatic (C2-C6) & 16 & 94.1 \\
Limbs (bilateral 2) & 19 & 100 \\
\hline Right & 7 & 36.8 \\
\hline Left & 12 & 63.1 \\
C2 & 12 & 63.1 \\
\hline C3 & 2 & 10.5 \\
\hline C4 & 2 & 10.5 \\
C5 & 2 & 10.5 \\
\hline C6 & 1 & 5.2 \\
Previous treatments & & \\
\hline Surg. interruption + stripping & 8 & 10.5 \\
\hline Low ligation +/- stripping SSV & 6 & 31.5 \\
CHIVA & 3 & 15.7 \\
\hline EVLA & 2 & \\
\hline
\end{tabular}

C2-C6: CEAP clinical classification; CHIVA: cure hemodinamique insuffisance veineuse ambulatoire; EVLA : endovenous laser ablation.

The limbs were investigated with the patient in standing position, by cross and longitudinal scanning at the groin, at the PR, at the calf and thigh; 16 symptomatic limbs (94.1\%) and three asymptomatic $(15.7 \%)$ with a time of reflux of more than $3 \mathrm{~s}[5,6]$ were selected for re-treatment. The outflow into the deep system and the anatomical variants were investigated on the bases of literature's information: variations of the SPJ location, SSV outflowing into other superficial or deep veins, other anatomical variations such as aneurysm or multiple outlets, different sources of reflux such as the medial gastrocnemious, the popliteal non-saphenous, the gluteal and lateral thigh perforators, the intersaphenous communicating vein, the medial accessory vein of the great saphenous (Giacomini) and the varicose veins of the sciatic nerve were investigated [7-16].

The potential presence of neovascularization by neoangiogenesis was investigated on the basis of the literature's recommendations searching for thin and tortuous veins of less than $2 \mathrm{~mm}$ in diameter connected with a residual saphenous stump (SS) or with other veins connected with the deep system or into thinner subcutaneous veins [17]. All the vascular connections with the major anatomical residuals were investigated both by DUS examination and surgical dissection.

Fourteen limbs $(76.3 \%)$ with VR of more than $3 \mathrm{~mm}$ in diameter [18] were surgically revised. 
Table 3. Treatment Performed in 19 Limbs of 17 Patients (Two Bilateral) Affected With VR at the PR

\begin{tabular}{lll}
\hline Treatment & N & \% \\
\hline Surgical revision interruption + sclerotherapy & 13 & 68.4 \\
Surgical revision interruption + short SSV stripping & 1 & 5.2 \\
USD-guided sclerotherapy & 4 & 21.0 \\
Conservative treatment & 1 & 5.2 \\
Postoperative sclerotherapy & 5 & 26.3 \\
Elastic compression & 19 & 100 \\
\hline
\end{tabular}

DUS: duplex ultrasound examination.

The interventions were performed in prone position, under local anesthesia and by direct dissection via a transverse surgical incision, more frequently performed at the PR, less frequently at different sites where the source of reflux was detected by preoperative DUS. In the cases where the previous intervention was performed at the PR, a careful direct surgical dissection was carried on from the superficial layers, through and below the fascia, and the residual veins were made free from the fibrotic surrounding tissue, deeper and close to the outflow into the popliteal vein or into other veins in the cases with anatomical variations of the confluence. When a long SS was found in the politeal fossa, the surgical dissection was performed taking care of the gastrocnemial veins, of the superficial sural nerve and artery [7-9]. In 13 limbs (68.4\%), the surgical interruption was combined with intraoperative foam sclerotherapy [18] with polidocanol, $3-5 \mathrm{~mL}$ at $1.5 \%$ of concentration by DUS-guided injection into the distal stump of the SSV or into other incompetent recurrent varices. The residual SSV ablation was mainly preformed by foam sclerotherapy to avoid surgical or thermal damages to the surrounding structures. In one case with a residual SSV of $12 \mathrm{~mm}$ in diameter, a short invagination stripping was preferred. Other sources of recurrent reflux, as perforators, communicating veins and tributaries of more than $3 \mathrm{~mm}$ in diameter were also found and interrupted. In 14 cases, the DUS and surgical findings could be compared. Four cases $(21.0 \%)$ with VR of smaller veins (less than $3 \mathrm{~mm}$ in diameter) [18] were treated by simple DUS-guided foam sclerotherapy by injection of polidocanol, 2 - $5 \mathrm{~mL}$ at $1.0 \%$ of concentration. In all the cases treated by surgery and/or foam sclerotherapy, a refrigerant padding (Veinalgic - trademark No. 011810546) and an elastic bandage compression were simultaneously applied. After $1-2 \mathrm{~h}$, the bandaging was replaced by an elastic compression stocking (CIZETA Medicali ${ }^{\circledR}$, Cuggiono, Milano, Italy) of various classes, from 12 to $30 \mathrm{~mm} \mathrm{Hg}$, which were kept in site for 7 days. One patient, who refused the intervention and sclerotherapy, was subjected to drug and elastic compression treatment. In five operated limbs $(26.3 \%)$, a postoperative foam sclerotherapy and compression were performed after 2 months (Table 3). The compression class of the elastic stockings applied after surgery, sclerotherapy or in combination with drug therapy, was chosen on the basis of noinvasive venous pressure measurements [19, 20].

All the treated limbs were controlled after treatment, and the surgical elimination of the sources of reflux and the vein occlusion after sclerotherapy were studied by DUS examination (mean follow-up 3.8 years, range 1 - 8). The comparison between the DUS and surgical findings was analyzed by the Fisher's exact test for a $2 \times 2$ table.

\section{Results}

Multiple residual varicose veins connected with a long SS at the SPJ were found in various combinations in 14 limbs $(73.6 \%)$, while in five (26.3\%), the SPJ was absent and different sources of reflux of VR at the PR were detected: one incompetent long SS (5.2\%) with a high outflow into the superficial femoral vein at the posterior surface of the middle thigh, one incompetent long SS outflowing into the medial accessory vein of the GSV (Giacomini) (5.2\%) and the non-saphenous popliteal perforator in two cases $(10.5 \%)$.

The more frequent anatomical residuals were a long SS at the SPJ, incompetent perforators $(10,52.7 \%)$ and the medial intersaphenous communicating veins $(4,21 \%)$ variously combined.

In four cases $(21.0 \%)$, a CC, which was visible at the clinical observation and was confirmed by the DUS examination, appeared to be composed by small tortuous veins of more than $2 \mathrm{~mm}$ in diameter and connected with an incompetent long SS. Such small veins did not correspond to the suggested criteria for their inclusion in the concept of neoangiogenesis [17]. Neither evidence of neovascularization by neoangiogenesis (Fisher's test: $\mathrm{P}=1$ ), nor VV belonging to the sciatic nerve was observed both by DUS and surgery. The anatomical findings are reported in Table 4.

In $13 / 14$ re-operated limbs $(92.8 \%)$, the surgical direct dissection confirmed the preoperative DUS anatomical findings (Fisher's test: $\mathrm{P}=1$ ).

One limb (5.2\%) which was previously operated on by our group developed a VR at the PR after 4 years. A residual nonsaphenous popliteal perforator was detected by DUS preoperative examination, while the surgical dissection demonstrated that the residual incompetent vein was a second SSV (SSV duplicity) of $9 \mathrm{~mm}$ in diameter which was missed at the previous intervention. In this case, the surgical ablation of the proximal SSV segment and foam sclerotherapy of the distal one were performed.

The elastic bandage, the refrigerant padding and the elastic compression stocking were well tolerated by all the patients.

In the 17 treated limbs, a successful clinical and DUS outcome was obtained and no residual sources of reflux were detected. One example of the combination of surgery and sclerotherapy is shown in Figure 1. In 12 limbs subjected to surgical revision and intraoperative foam sclerotherapy and in the four cases subjected to DUS-guided foam sclerotherapy, a complete fibrotic occlusion of the SSV was found at the DUS follow-up (statistically unparsable).

Minor complications occurred in 4/14 operated limbs (28.4\%): skin pigmentation after peripheral foam sclerotherapy in two cases; one post-sclerotherapy superficial phlebitis which solved in a couple of weeks by drug therapy; one subfascial hematoma in the limb re-treated for VR from a residual 
Table 4. Residual Varicose Veins and Anatomical Findings Detected by DUS Examination in 19 Limbs and by Direct Surgical Dissection in 14

\begin{tabular}{|c|c|c|}
\hline Sites of VR & $\mathbf{N}$ & $\%$ \\
\hline Sapheno-popliteal junction & 14 & 73.6 \\
\hline Saphenous stump $+/-$ residual tributary $(1$ aneurysmatic $=5.2 \%)$ & 13 & 68.4 \\
\hline SSV persistence in a previous duplicity & 2 & 10.5 \\
\hline Popliteal perforator (non saphenous) (combined) & 2 & 10.5 \\
\hline Medial gastrocnemius perforator & 2 & 10.5 \\
\hline Medial communicating SSV-GSV & 3 & 15.7 \\
\hline Medial accessory (Giacomini) & 1 & 5.2 \\
\hline Gluteal perforator & 1 & 5.2 \\
\hline Lateral perforator of the thigh & 1 & 5.2 \\
\hline VV of the sciatic nerve & 0 & 0 \\
\hline Neovascularization by neoangiogenesis (suspected) & 0 & 0 \\
\hline Complex collateral circulation (cavernoma) & 4 & 21.0 \\
\hline Sapheno-popliteal region & 5 & 26.3 \\
\hline Saphenous Stump - outflow into superficial femoral & 1 & 5.2 \\
\hline SSV outflowing into the medial accessory (Giacomini) & 1 & 5.2 \\
\hline Popliteal perforator (non saphenous) & 2 & 10.5 \\
\hline Medial gastrocnemius perforator & 2 & 10.5 \\
\hline VV of the sciatic nerve & 0 & 0 \\
\hline Neovascularization by neoangiogenesis & 0 & 0 \\
\hline Complex collateral circulation (cavernoma) & 0 & 0 \\
\hline
\end{tabular}

Comparison DUS/surgery analyzed by exact Fisher's test $(P=1)$. SSV: short saphenous vein; GSV: great saphenous vein; VV: varicose vein. Sapheno-politeal junction: normal outflow of the SSV. Popliteal region: absence of the SSV outflow. In cursive writing 1 aneurysmatic of the 13 saphenous stumps. Percentages calculated on the total of 19 limbs.

double SSV. The latter was treated by drug and compression therapy for 2 months before a satisfactory reduction of the hematoma and relapses of symptoms were obtained. A significant subjective and objective clinical improvement was obtained in the patient subjected to conservative treatment (mean followup 3.8 years, range $1-8$ ).

\section{Discussion}

From our previous studies, the prevalence of the cases affected with VR at the SFJ clearly emerged which led us to focus the research at the groin more than at the $\operatorname{PR}[1,2]$, where the data obtained from the different centers appeared to be scarcely detailed. Nevertheless, it was possible to assess the presence of long SS and other residual incompetent veins being the more frequent causes of recurrence.

The present study is based on a very small casuistry: 19 limbs affected with isolated VR at the PR over a total of 207 affected with VR (9.1\%) and over a total of 1,831 limbs subjected to previous surgery for primary varicose veins of the lower limbs $(1 \%)$ in a period of 10 years (Table 1$)$; such a small number is not so far from the ones reported in the literature. Other authors calculated that varicosities of the PR are combined with varicose veins from GSV incompetence with a frequency ranging from a minimum of $36.6 \%$ to a maximum of $46 \%$, while incompetent veins at the PR represent the only source of reflux with a frequency ranging from a minimum of $3.7 \%$ up to a maximum of $28.5 \%$ of the cases [21-26]. VR at the PR represents a low percentage of the limbs affected with postoperative VR at the junctions (mean 21.6\%; range: 3.7 50) $[1,2,24,27]$. Therefore, it can be easily understood why VR at the PR is observed so rarely.

The interval between the first intervention and the VR appearance (mean 4.8 years; range: 1 - 12) is variable and cannot be useful for better understanding the role of the disease progression which must be taken into consideration too.

The majority of the patients were affected with symptoms from venous insufficiency $(94.1 \%)$ and the clinical class C2 was prevalent. In $17 / 19$ limbs $(89.4 \%)$, the first intervention consisted with surgical interruption +/- SSV stripping including the three subjected to the so-called CHIVA procedure, which consists with simple ligation/s [4]. One of the two SSVs which were treated by EVLA appeared to be still occluded at 1 year, but the proximal segment was still patent, incompetent and connected with incompetent varicose collaterals. The second one was entirely patent and incompetent at 3 years (Table 2).

Before examining our cases, we reviewed the more recent 

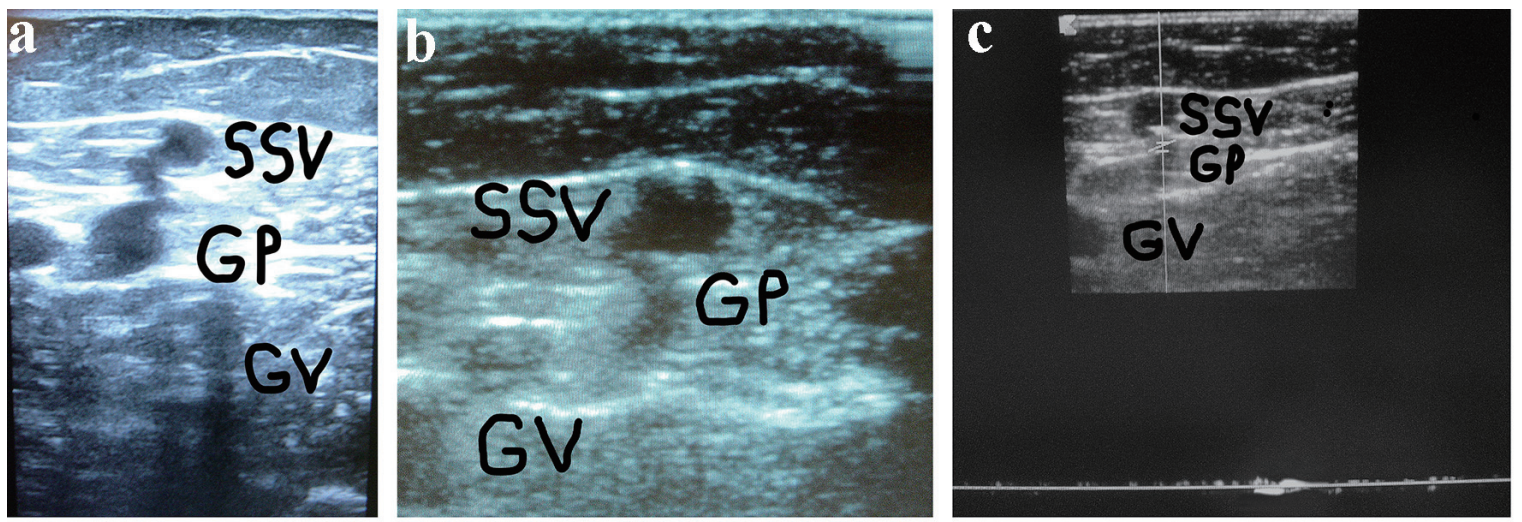

Figure 1. (a) A woman of 67 years of age. Appearance of symptomatic VR in the PR 4 years after the previous surgical procedure for varicose veins at the PR. Cross scanning of DUS examination at the PR: incompetent gastrocnemius perforator (GP) connected with the long residual SSV stump. The internal gastrocnemius vein (GV) is visible. (b) Treatment: SPJ surgical interruption and intraoperative DUS-guided foam sclerotherapy of gastrocnemius perforator (GP) and residual SSV. DUS examination after 30 days: the SS stump is not compressible and partially hyper-echogenic from early fibrosis (SSV), the gastrocnemius perforator (GP) is hyper-echogenic from early complete fibrosis in the subfascial segment, the internal gastrocnemius vein (GV) is patent and compressible. (c) DUS examination after 30 days: the gastrocnemius perforator (GP) is occluded with no flow into the lumen, the SS stump is not compressible and hyper-echogenic from advanced fibrosis (SSV), the internal gastrocnemius vein (GV) is patent and compressible.

literature where the causes of VR at the PR have been described: incomplete diagnostic and surgical procedures, recanalization after sclerotherapy or endovascular treatments and the neonagiogenetic hypothesis [24, 27-33]. The importance of performing a complete investigation of the anatomical causes of VR at the PR recently led some authors to employ the threedimensional computed tomography venography [34].

Neovascularization by neoangiogenesis is a physiological process following traumas, wounds, hematomas and thrombosis; therefore, it must not be surprising to find it in the thickness of the postoperative scar tissue $[1,2]$. On the other hand, the natural history of varicose evolution and disease progression can fully explain the appearance of new proximal and/or peripheral varices, as often happens in the primary disease $[5$, 19, 22, 25].

Seventeen patients' limbs were previously treated in different centers and it was impossible to compare the results of DUS examination performed before the first intervention with our DUS and surgical findings. Two cases were previously treated in our center and the DUS and surgical data emerging from the first and the second intervention could be compared. In one limb, the cause of relapse was an SSV duplicity which was observed at the second intervention after 2 years, but it was not visible at the first observation. In one limb, the cause of VR was the presence of an incompetent gastrocnemius perforator which was not visible at the first observation. Therefore, it must be assumed that some of the anatomical residuals became dilated and incompetent after the first procedure owing to the disease progression rather than incomplete diagnosis and treatment. Nevertheless, while the disease progression has been seldom investigated and discussed as a cause of VR, a relevant importance of the anatomical variations at the SPJ is highlighted by several studies, especially the ones concerning the variations of the SSV outlet, which can be found in the PR in more of the $30 \%$ of the cases [10-16] where such variations must be carefully investigated to make an effective diagnostic and therapeutic approach.

A further critical point, the so-called cavernoma, almost never subjected to research, but often invoked and related to neoangiogenesis during congress presentations, was discussed in the previous publications $[1,2]$ and can be confirmed by the present study: the residual collateral incompetent veins can lead to the development of an anarchic CC and seems to represent a consequence of reflux more than a tumor-like cause of VR.

It can be useful to describe one example of the potential complexity of the anatomy and diagnostic implications of some recurrent limbs at the SPR. A young lady of 42 years of age, who was operated on for VVLL at the SPJ, developed after 2 years a symptomatic VR in the SPR which appeared to belong to a residual SSV. The preliminary DUS examination demonstrated an aneurysm of the proximal long SSV stump connected with an incompetent collateral vein (Fig. 2a). A more extended DUS examination detected the following sources of reflux simultaneously present in the same limb: double high non-saphenous popliteal perforator, connection with the medial accessory of the GSV (Giacomini), one low gastrocnemius and one peroneal perforator (Fig. 2b). The patient was re-operated on by multiple surgical interruptions and intraoperative DUS-guided foam sclerotherapy and compression.

The comparison between the DUS and surgical findings, which were overlapping in 17/18 limbs (94.4\%) (Table 4), seems to indicate that the extended and detailed preoperative DUS investigation is reliable and fundamental for the assessment of the therapeutic choice and treatment strategy.

The combination of surgery and sclerotherapy was adopted in our cases to obtain the more stable results, to minimize the surgical approach in order to avoid complications by traumatic or thermal damage to the superficial nerve and artery [6$8]$ and finally to perform fast and inexpensive procedures [18]. 

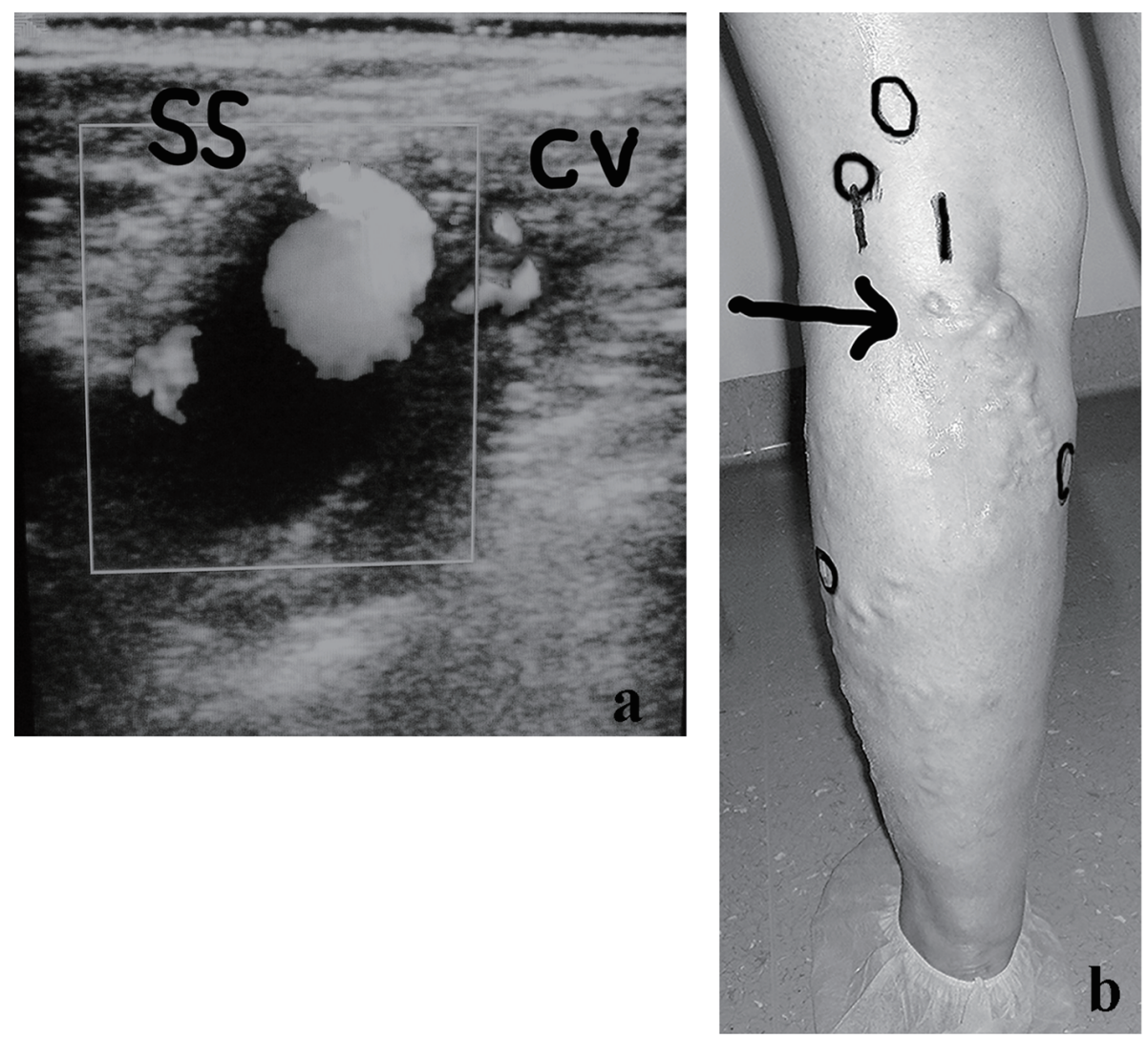

Figure 2. (a) A woman of 42 years of age, operated on for VVLL at the SPJ. Appearance of symptomatic VR in the PR, belonging to a residual SSV, after 2 years. The clinical and preliminary DUS examination demonstrated an aneurysm of the proximal long SSV incompetent stump (SS) connected with a small incompetent collateral vein (CV). (b) Preoperative skin mapping. A more extended DUS examination detected the following combined sources of reflux which are visible in the preoperative skin drawing: aneurysm of the residual SS, double high non-saphenous popliteal perforator, connection with the medial accessory of the GSV as main causes of VR at the PR; low gastrocnemius and peroneal perforators. The black arrow indicates the SS aneurysm. The black circles correspond to the four incompetent perforators.

A low number of limbs $(5 / 19,26.3 \%)$ required postoperative foam sclerotherapy and compression so it can be affirmed that an extensive elimination of reflux combined with intraoperative foam sclerotherapy can often lead to a spontaneous relapse of the peripheral recurrent varicosities. No complications were observed after sclerotherapy, while minor acceptable complications occurred in the $4 / 14$ operated limbs $(28.5 \%)$ without further sequelae.

The bandaging with refrigerant padding and the choice of the elastic stocking class of compression by venous pressure measurement criteria $[17,18]$ appeared to be helpful in the postoperative period and were not followed by patient's complaints.

\section{Conclusions}

Overlapping data emerged by the preoperative DUS examination and the intraoperative findings, therefore it is possible to affirm that a careful DUS examination can lead to the detailed knowledge of the anatomical causes of VR at the PR and makes possible to make the best choice of treatment. Neovas- cularization by neoangiogenesis has been excluded as a cause of VR at the PR and SPJ in the studied limbs. The development of a $\mathrm{CC}$, which has been sometimes invoked for explaining the onset of VR, appears to be a consequence of reflux more than a cause. Residual SS and tributaries, communicating and perforating veins, variously located and combined, which can be missed by inadequate diagnostic and surgical procedures or may be expression of the disease progression, appeared to be the main causes for the onset of VR in the PR.

Re-treatment by surgical revision combined with intraoperative DUS-guided foam sclerotherapy, followed by selected elastic compression, seems to represent a simple, effective and cheap procedure for the larger recurrent varices at the PR. USD-guided foam sclerotherapy and elastic compression seem the more feasible alternative for the smaller ones.

\section{Acknowledgments}

This study was supported by CIZETA Medicali, Cuggiono, Milano, Italy and presented at the 30th National Annual Congress of the Italian Society of Phlebolymphology, Ferrara, Italy 
on October 20 - 22, 2016.

\section{Conflicts of Interest}

The authors do not declare any conflicts of interest.

\section{References}

1. Corcos L. Le cause di recidiva inguinale e poplitea dopo chirurgia dell'insufficienza venosa superficiale. In Tondi P. Patologie del sistema venoso e linfatico. Verducci Ed. Roma. 2013: p. 235-246.

2. Corcos L, Aloi T, Alonzo U, et Al. Postoperative Varicose Recurrence at the Junctions. A Multicentric Study of 1.056 Patients by the Italian Society of Phlebolymphology. Conclusive Considerations. Acta Phlebol. 2014;15:69-78.

3. Caggiati A, Bergan JJ, Gloviczki P, Eklof B, Allegra C, Partsch H,. J Vasc Surg. 2005;41(4):719-724.

4. Franceschi C. [Ambulatory and Hemodynamic Treatment of Venous Insufficiency (Chiva Cure)]. J Mal Vasc. 1992;17(4):291-300.

5. Labropoulos N, Touloupakis E, Giannoukas AD, Leon M, Katsamouris A, Nicolaides AN. Recurrent Varicose Veins: Investigation of the Pattern and Extent of Reflux with Color Flow Duplex Scanning. Surgery. 1996;119(4):406409.

6. Belcaro G, Veller M, Nicolaides AN, Cesarone MR, Christopoulos D, DeSanctis MT, Dhanjil S, et al. Noninvasive Investigations in Vascular Disease. St Mary's Fellows. Isvi (Italian Society for Vascular Investigations). Angiology. 1998;49(9):673-706.

7. Schweighofer G, Muhlberger D, Brenner E. The Anatomy of the Small Saphenous Vein: Fascial and Neural Relations, Saphenofemoral Junction, and Valves. J Vasc Surg. 2010;51(4):982-989.

8. Kerver AL, van der Ham AC, Theeuwes HP, Eilers PH, Poublon AR, Kerver AJ, Kleinrensink GJ. The Surgical Anatomy of the Small Saphenous Vein and Adjacent Nerves in Relation to Endovenous Thermal Ablation. J Vasc Surg. 2012;56(1):181-188.

9. Uhl JF, Gillot C. Anatomy and Embryology of the Small Saphenous Vein: Nerve Relationships and Implications for Treatment. Phlebology. 2013;28(1):4-15.

10. Kosinski C. Observations on the Superficial Venous System of the Lower Extremity. J Anat. 1926;60(Pt 2):131142.

11. Corcos L, Macchi C, de Anna D, Procacci T, Peruzzi G, Giannelli F, Gheri G, et al. The Anatomical Variables of the Sapheno-Popliteal Junction Visualization by Radiological and Echographic Examinations. Ital J Anat Embryol. 1996;101(1):15-28.

12. Simkin R. Varices, Ulceras y Angiodisplasias. Libreros Lopez Editores. Cordoba, Buenos Aires. 1991:14-16.

13. Stella A. Le varici della piccola safena. In D'Addato M. Patologia Venosa. Aspetti particolari. Ed. Minerva Medica. Torino. 1994:31-47.
14. Blachemaison P, Greney P. Atlante anatomico delle vene superficiali degli arti inferiori. Ed. Minerva Medica. Torino. 1997:98-121.

15. Nakayama M. The Incidence, Clinical Importance and Management of Incompetent Gastrocnemius Vein. Ann Vasc Dis. 2016;9(1):35-41.

16. Delis KT, Knaggs AL, Hobbs JT, Vandendriessche MA. The Nonsaphenous Vein of the Popliteal Fossa: Prevalence, Patterns of Reflux, Hemodynamic Quantification, and Clinical Significance. J Vasc Surg. 2006;44(3):611619.

17. Kundu S, Lurie F, Millward SF, Padberg F, Jr., Vedantham S, Elias S, Khilnani NM, et al. Recommended Reporting Standards for Endovenous Ablation for the Treatment of Venous Insufficiency: Joint Statement of the American Venous Forum and the Society of Interventional Radiology. J Vasc Surg. 2007;46(3):582-589.

18. Belcaro G, Dugall M, Corsi M, Agus GB, Ippolito E. Superficial Venous Incompetence: Low-Cost Outpatient Minisurgery, Sclerotherapy and Combined Procedure as a Management Plan. Costs and Efficacy. A 20-Year, Follow-up Registry. Minerva Chir. 2016;71(4):223-232.

19. Spina T, Ferlaino E, Pontello D, Corcos L. The Value of Doppler Venous Pressure Index in Chronic Venous Disease of the Lower Limbs. J Curr Surg. 2015;5(4):188198.

20. Corcos L, Pontello D, Spina T. Elastic Compression Treatment of Chronic Superficial Venous Insufficiency of the Lower Limbs Based on Doppler Venous Pressure Index Measurements. Veins \& Lymphatics. 2015;4(26):2230-2232.

21. Labropoulos N, Giannoukas AD, Delis K, Kang SS, Mansour MA, Buckman J, Katsamouris A, et al. The Impact of Isolated Lesser Saphenous Vein System Incompetence on Clinical Signs and Symptoms of Chronic Venous Disease. J Vasc Surg. 2000;32(5):954-960.

22. Ferro A, Kaumann AJ, Brown MJ. Beta 1- and Beta 2-Adrenoceptor-Mediated Relaxation in Human Internal Mammary Artery and Saphenous Vein: Unchanged Beta- and Alpha-Adrenoceptor Responsiveness after Chronic Beta 1-Adrenoceptor Blockade. Br J Pharmacol. 1993;109(4):1053-1058.

23. Wong JK, Duncan JL, Nichols DM. Whole-Leg Duplex Mapping for Varicose Veins: Observations on Patterns of Reflux in Recurrent and Primary Legs, with Clinical Correlation. Eur J Vasc Endovasc Surg. 2003;25(3):267-275.

24. Lin JC, Iafrati MD, O'Donnell TF, Jr., Estes JM, Mackey WC. Correlation of Duplex Ultrasound Scanning-Derived Valve Closure Time and Clinical Classification in Patients with Small Saphenous Vein Reflux: Is Lesser Saphenous Vein Truly Lesser? J Vasc Surg. 2004;39(5):1053-1058.

25. Labropoulos N, Kokkosis AA, Spentzouris G, Gasparis AP, Tassiopoulos AK. The Distribution and Significance of Varicosities in the Saphenous Trunks. J Vasc Surg. 2010;51(1):96-103.

26. Qureshi MI, Lane TR, Moore HM, Franklin IJ, Davies AH. Patterns of Short Saphenous Vein Incompetence. Phlebology. 2013;28(Suppl 1):47-50.

27. Creton D. [125 Reinterventions for Recurrent Popliteal 
Varicose Veins after Excision of the Short Saphenous Vein. Anatomical and Physiological Hypotheses of the Mechanism of Recurrence]. J Mal Vasc. 1999;24(1):3036.

28. Tong Y, Royle J. Recurrent Varicose Veins after Short Saphenous Vein Surgery: A Duplex Ultrasound Study. Cardiovasc Surg. 1996;4(3):364-367.

29. Rettori R. [Postoperative Recurrence of Varicosities at the Level of the Popliteal Fossa. Anatomic Data Guiding the Ultrasonographic Exploration and Surgical Sequelae]. J Mal Vasc. 1998;23(1):54-60.

30. Pukacki F, Zielinski P, Checinski P, Oszkinis G. [Short Saphenous Vein Incompetence as a Cause of Recurrent Varicose Veins]. Wiad Lek. 2003;56(1-2):28-33.
31. Perrin M, Gillet JL. [Recurrent Varices at the Groin and Popliteal Fossa after Surgical Treatment]. J Mal Vasc. 2006;31(5):236-246.

32. O'Donnell TF Jr, Iafrati MD. The Small Saphenous Vein and Other 'Neglected' Veins of the Popliteal Fossa: A Review. Phlebology. 2007;22(4):148-155.

33. Cina G, Narese D, Amicucci V, Filipponi M, Snider F. Recurrent Varicose Veins of the Legs: A Single Centre Experience. Clin Ter. 2014;165(4):183-186.

34. Kim SY, Park EA, Shin YC, Min SI, Lee W, Ha J, Kim SJ, et al. Preoperative Determination of Anatomic Variations of the Small Saphenous Vein for Varicose Vein Surgery by Three-Dimensional Computed Tomography Venography. Phlebology. 2012;27(5):235-241. 